\title{
Delignified Wood-based Highly Efficient Solar Steam Generation Device via Promoting Both Water Transportation and Evaporation
}

\author{
Yuming He, ${ }^{\mathrm{a}}$ Huayang Li, ${ }^{\mathrm{a}}$ Xuelian Guo, ${ }^{\mathrm{b}}$ and Rongbo Zheng ${ }^{\mathrm{a}, *}$
}

\begin{abstract}
Wood-based solar steam generation holds great promise in alleviating fresh water crises due to its advantages: light absorbability, thermal management, water transpiration, and water evaporation. Although tremendous efforts have been made to improve wood-based solar steam generation devices, they mainly have focused on the optimization of photothermal materials to optimize light absorbability and thermal management to enhance efficiency of steam generation. This research demonstrates that delignified wood (DL-wood) can further improve the efficiency of steam generation via increasing both the water transportation and water evaporation. The results show that after placing carbon nanotubes (CNTs) on DL-wood, the efficiency of steam production is higher than that of natural wood coated with CNTs by $20 \%$ under ambient sunlight conditions. DL-wood with CNTs has the following advantages: (1) it is stable, available, and easy to extend; (2) it does not pollute the environment and will not cause discoloration or dregs when used; and (3) it is a promising efficiency-enhancing solution for renewable and portable solar power generation.
\end{abstract}

Keywords: Solar steam generation; Fast water transportation; Fast water evaporation; Delignified wood

Contact information: a: Yunnan Province Key Laboratory of Wood Adhesives and Glued Products, College of Chemical Engineering, Southwest Forestry University, Kunming 650224, P. R. China; $b$ : Wetland College, Southwest Forestry University, Kunming 650224, P. R. China;

*Corresponding author: zhengrbzy@ hotmail.com

\section{INTRODUCTION}

Solar steam generation is one of the most promising, sustainable techniques for desalination and water purification, and it has attracted great attention (Ghasemi et al. 2014; Gamelas and Ferraz 2015; Ito et al. 2015). There are four key factors that affect the efficiency of solar generation devices: sunlight absorbability, thermal management, water transportation, and water evaporation (Jin et al. 2016; Ni et al. 2016; Wang et al. 2016a). Various structural materials have been designed and developed for this application (Zielinski et al. 2016), such as plasmonic metal particles for localizing heat generation (Wang et al. 2016b; Zhou et al. 2016a,b), bilayered forms with a black surface for efficient light absorption and thermal management (Li et al. 2016; Shi et al. 2017), and carbonaceous materials with broadband sunlight absorptivity and hydrophilic surface for water transpiration (Ghasemi et al. 2014). More recently, inspired by the water transpiration behavior of trees, the use of carbon nanotube (CNT)-modified horizontally cut wood (Chen et al. 2017; Wang, et al. 2017), graphite-coated vertically cut wood (Li et al. 2018), grapheme oxide-coated wood (Liu et al. 2017b), surface carbonization, vertically cut wood (Liu et al. 2017a; Xue et al. 2017; Zhu et al. 2017), and Chinese inkcoated wood (Yang et al. 2018) have been demonstrated as efficient solar steam generation devices (Wright et al. 2013). This is due to the systematic optimizations of 
light absorbability (Jiang et al. 2016), thermal management, and water transpiration enabled by the unique structure consisting of a carbonaceous surface as a light absorber, insulating the wood matrix as a thermal blocker and hierarchical micro/nanochannels as a water transportation pathway.

Although the above-mentioned wood-based solar steam generation devices have been demonstrated to greatly enhance the efficiency of solar steam generation, they mainly focused on various photothermal materials such as CNT, graphite, graphene oxide, surface carbonization, and Chinese ink combined with hierarchical porous structures to improve both the sunlight absorbability and the thermal management. There are few reports on enhancing the efficiency of solar steam generation devices via improving both the water transportation ability and water evaporation of wood-based devices (Chen et al. 2017). Wood cell walls are primarily composed of fiber tracheids and vessels with lumen diameters ranging from 10 to $100 \mu \mathrm{m}$, which act as pathways for rapid water transport (Zhong et al. 2018a). In wood cell walls, cellulose microfibrils are embedded within lignocellulosic matrices, in which the lignin reinforces the cell walls to improve the mechanical properties and also reduces the permeability of water.

The objective of the current study was to test the hypothesis that the efficiency of solar steam generation devices can be improved by removing lignin from the wood. After the removal of hydrophobic lignin, the delignified wood (DL-wood) not only preserved the original hierarchical structure of wood, but also increased hydrophilicity and possessed more micro/nano pores in the cell walls and cell wall corners, which promotes both water transportation and evaporation from the bottom to the top surface of wood. When the sunlight illustrates the CNTs-coated DL-wood, the black surface will absorb the sunlight and generate localized heat at the water-air interface to evaporate via increasing the local temperature (Zhong and Huang 2019). With a sufficient supply of bottom water to the CNTs coated top wood surface (Zheng et al. 2016; Zhong et al. $2018 b$ ) and fast water evaporation, the efficiency of CNTs modified DL-wood device might increase compared with that of CNTs modified natural wood device under ambient sunlight illumination.

This study reports the development of CNTs-modified DL-wood solar steam generation devices by replacing the natural wood with DL-wood, which is obtained by $\mathrm{H}_{2} \mathrm{O}_{2}$ steam delignification. DL-wood is used as a substrate to be modified with CNTs by cutting along the direction vertical to the growth direction of trees. The water transportation and evaporation rates were characterized by measuring the transport distance of dye aqueous solutions and the mass change of water after illuminating to ambient sunlight. Compared with CNTs modified natural wood device, the efficiency of CNT modified DL-wood devices increased from $60 \%$ to $73 \%$ in this study.

\section{EXPERIMENTAL}

\section{Materials and Chemicals}

Basswood slices with a diameter of $4 \mathrm{~cm}$ and a thickness of $0.5 \mathrm{~cm}$ were used in this study. These samples have the original channels in wood aligned perpendicular to the wood plane. DL-wood was obtained by radially cutting the wood trunk, also called Rawood. The chemicals used in removing lignin from wood were hydrogen peroxide $(30 \%$ solution, Sino pharm, Beijing, China) and CNTs (Sino pharm). The solvents used were ethanol alcohol (Sino pharm) and deionized water. 


\section{Delignification of the Wood}

The precut wood slices were steam delignified by being placed on grids with the unit size of $5 \mathrm{~mm} \times 5 \mathrm{~mm}$, which was placed about $2 \mathrm{~cm}$ above an $\mathrm{H}_{2} \mathrm{O}_{2}$ boiling aqueous solution (30 wt\%) (Li et al. 2019). When the yellow color of the sample disappeared (2 to $4 \mathrm{~h}$ ), the samples were removed and rinsed with cold water and ethanol. The DL-wood samples were stored in ethanol.

\section{Synthesis of DL-wood/CNTs}

Commercial CNTs powder was dispersed in acetone to make the CNTs solution. These wood samples were immersed in the solution of CNTs, then taken out and dried in air. This process was repeated several times to coat CNTs to the amount of about $0.4 \mathrm{wt} \%$ of wood with different treatments, resulting in the final product of CNTs-coated wood (Zheng et al. 2015; Chen et al. 2017).

\section{Measurements and Characterizations}

The morphologies of the samples were characterized by a scanning electron microscope (SEM, TESCAN VEGA3, Brno, Czech Republic). The lignin contents were measured according to TAPPI T222 om-11 (2011). A universal material machine (ProLine z020tn, Zwick, Ulm, Germany) was used to measure the mechanical properties.

\section{RESULTS AND DISCUSSION}

\section{Lignin Content and Properties}

The CNTs modified DL-wood solar steam generation device is shown in Fig. 1. First, DL-wood was prepared by delignification of natural basswood via $\mathrm{H}_{2} \mathrm{O}_{2}$ steam. CNTs were coated on the surface of DL-wood. Finally, the device was put on the surface of water in a glass beaker to generate steam under ambient sunlight.

As shown in Fig. 2a, the lignin content of basswood can be decreased from $22.5 \%$ (natural wood) to $12.3 \%$ (half DL-wood), to $1.01 \%$ (DL-wood) when the $\mathrm{H}_{2} \mathrm{O}_{2}$ steam was prolonged from $2 \mathrm{~h}$ to $4 \mathrm{~h}$, respectively. Notably, the delignified wood with $1.01 \%$ lignin content was still strong enough to be exploited in the solar steam generation device since the mechanical strength of the DL-wood in wet state and dry state is $0.42 \mathrm{MPa}$ and 4.5 $\mathrm{MPa}$, respectively. The microstructures of the natural and DL-wood were characterized by scanning electron microscopy (SEM). Figure 2c to $2 \mathrm{f}$ show the SEM images of the basswood before and after delignification. There are massive lumina with the diameter in the range from $10 \mu \mathrm{m}$ to $50 \mu \mathrm{m}$ (Ito et al. 2015). High-magnification SEM images reveal that the natural wood possesses dense, smooth cell wall corners and the middle lamella. Compared with natural wood, massive microscale pores were generated in the cell walls and cell wall corners after steam delignification, which promotes the water transportation and evaporation to the top surface (Fig. $2 \mathrm{c}$ and $2 \mathrm{~d}$ ).

To investigate the water transportation capacity, a water transportation experiment was designed. As shown in Fig. 3, $5 \mathrm{~mm}$ thick of natural wood and DL-wood were put into dye solution to observe the distance dye traveled after a certain time. As shown in Figs. 3c and 3d, the dye in the DL-wood were always transformed upwards by a greater distance, which indicates that the DL-wood has better water transportation capabilities than natural wood. 

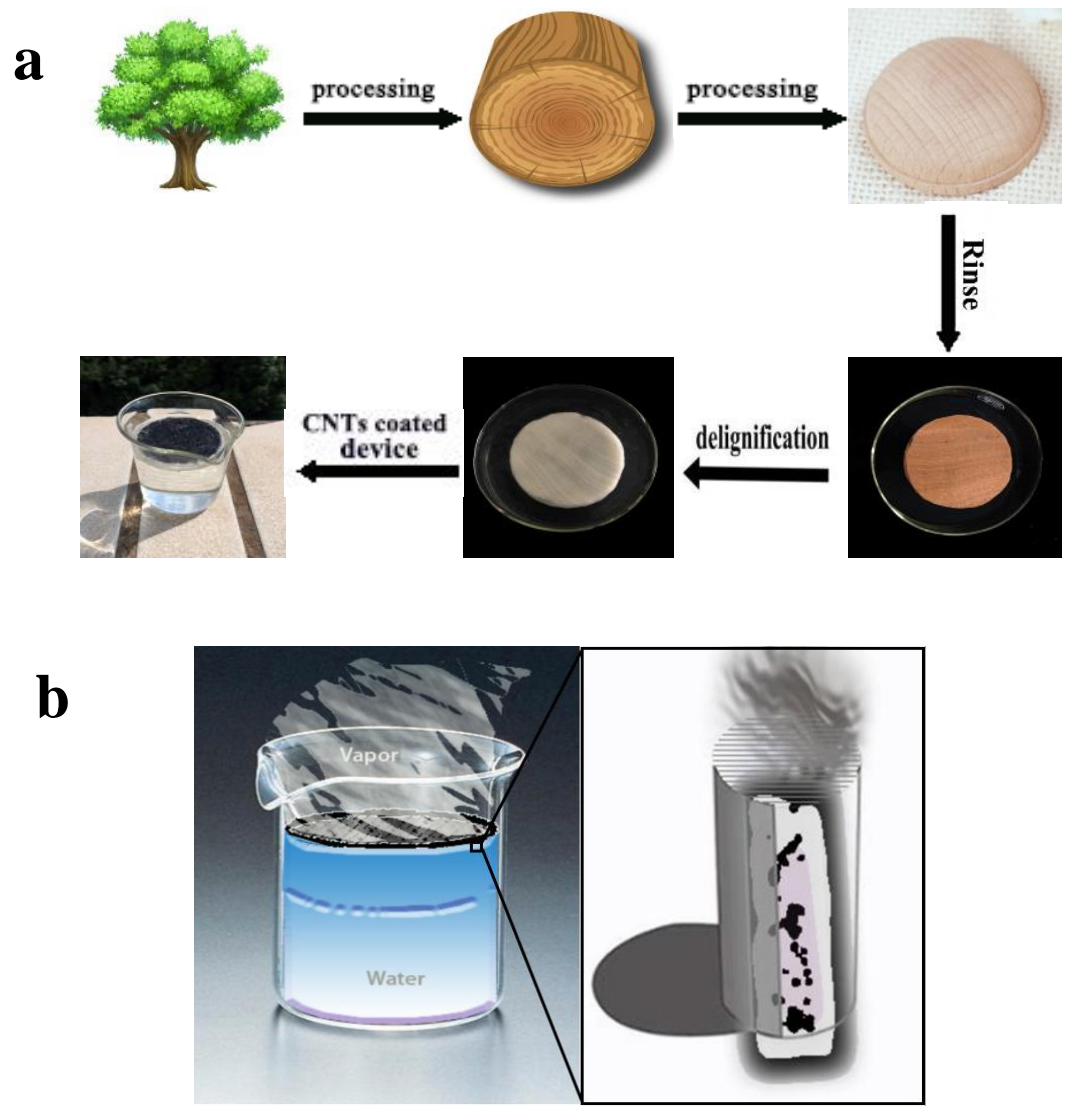

Fig. 1. (a) The preparation process of DL-wood/CNTs. (b) A schematic drawing of an DLwood/CNTs device that absorbs sunlight and heat to generate water vapor on the surface of the wood and approximate working drawing of a vessel channel, after the water molecules reach the top, the water molecules release rapidly through the local heat provided by the CNTs

To verify the superiority of DL-wood compared with natural wood in the evaporation of water, water-saturated DL-wood and natural wood were placed under 1 sun conditions for self-evaporation. Microholes and smoother vessel channels were generated via the removal of hydrophobic lignin, leading to faster evaporation of water under sunlight conditions than natural wood. DL-wood and natural wood were subjected to water self-volatization for 8 cycles under sunny (condition 1) conditions. The water evaporation of DL-wood was $0.261 \mathrm{~kg} \mathrm{~m}^{-2} \mathrm{~h}^{-1}, 0.245 \mathrm{~kg} \mathrm{~m}^{-2} \mathrm{~h}^{-1}, 0.276 \mathrm{~kg} \mathrm{~m}^{-2} \mathrm{~h}^{-1}, 0.267$ $\mathrm{kg} \mathrm{m}^{-2} \mathrm{~h}^{-1}, 0.259 \mathrm{~kg} \mathrm{~m}^{-2} \mathrm{~h}^{-1}, 0.268 \mathrm{~kg} \mathrm{~m}^{-2} \mathrm{~h}^{-1}, 0.250 \mathrm{~kg} \mathrm{~m}^{-2} \mathrm{~h}^{-1}$, and $0.254 \mathrm{~kg} \mathrm{~m}^{-2} \mathrm{~h}^{-1}$, while that of natural wood is $0.228 \mathrm{~kg} \mathrm{~m}^{-2} \mathrm{~h}^{-1}, 0.220 \mathrm{~kg} \mathrm{~m}^{-2} \mathrm{~h}^{-1}, 0.234 \mathrm{~kg} \mathrm{~m}^{-2} \mathrm{~h}^{-1}, 0.231 \mathrm{~kg} \mathrm{~m}^{-2} \mathrm{~h}^{-}$ ${ }^{1}, 0.225 \mathrm{~kg} \mathrm{~m}^{-2} \mathrm{~h}^{-1}, 0.234 \mathrm{~kg} \mathrm{~m}^{-2} \mathrm{~h}^{-1}, 0.225 \mathrm{~kg} \mathrm{~m}^{-2} \mathrm{~h}^{-1}, 0.223 \mathrm{~kg} \mathrm{~m}^{-2} \mathrm{~h}^{-1}$, respectively. As shown in Fig. 4b, the enhancement factor of evaporation of DL-wood vs. natural wood is $12 \%$ to $18 \%$.

Under ambient sunlight (light intensity of $0.98 \mathrm{~kW} \mathrm{~m}^{-2}$, ambient temperature of 30 ${ }^{\circ} \mathrm{C}$ ) for $10 \mathrm{~min}$, the water loss for the blank water control group, the natural wood/CNTs group, the half DL-wood/CNTs group, and the DL-wood/CNTs group were $0.08 \mathrm{~kg} / \mathrm{m}^{2}$, $0.14 \mathrm{~kg} / \mathrm{m}^{2}, 0.17 \mathrm{~kg} / \mathrm{m}^{2}$, and $0.19 \mathrm{~kg} / \mathrm{m}^{2}$, respectively. As illustrated in Fig. $4 \mathrm{c}$, after $1 \mathrm{~h}$, the water loss of the blank water control group, the natural wood/CNTs group, the half DL-wood/CNTs group, and the DL-wood/CNTs group were $0.79 \mathrm{~kg} / \mathrm{m}^{2}, 1.24 \mathrm{~kg} / \mathrm{m}^{2}, 1.31$ 
$\mathrm{kg} / \mathrm{m}^{2}$, and $1.40 \mathrm{~kg} / \mathrm{m}^{2}$, respectively.
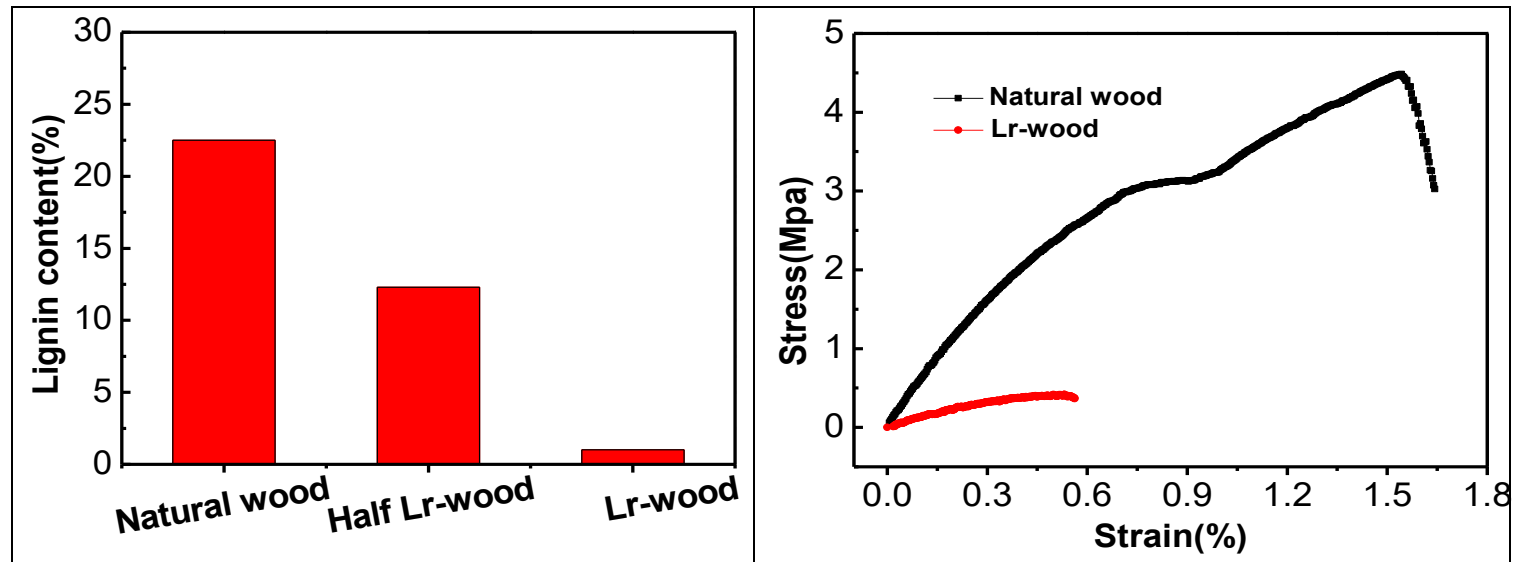

a

b
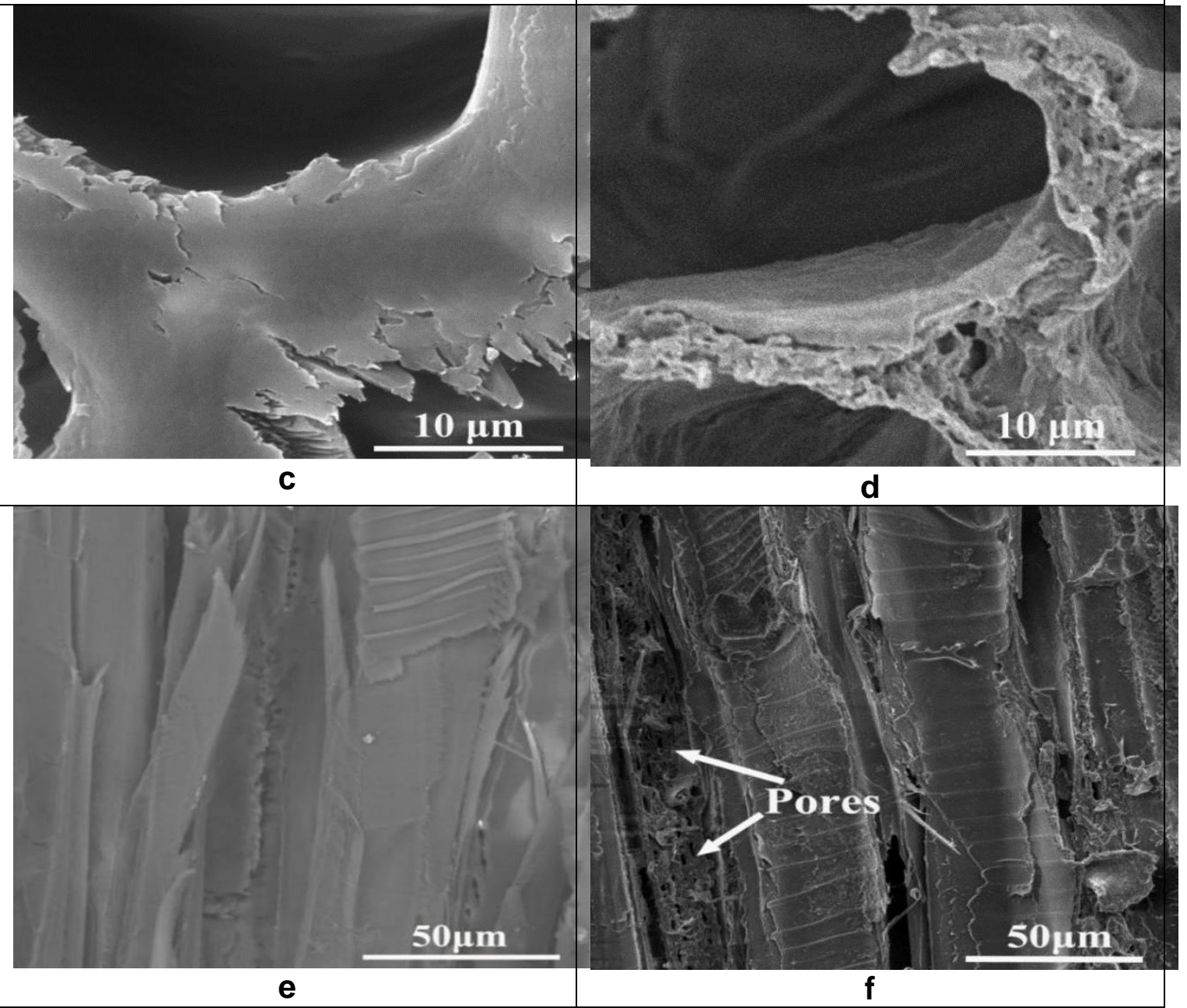

Fig. 2. (a) Lignin content of natural wood, half DL-wood and DL-wood. (b) Experimental stressstrain curves for the DL-wood in wet state. SEM images of $(c, e)$ natural wood and (d, f) DL-wood.

The water evaporation caused by the wind factor was subtracted since the outdoor experiment was influenced by the wind. The steam generation rate of the last four control 
groups was summarized as: $0.48 \mathrm{~kg} \mathrm{~m}^{-2} \mathrm{~h}^{-1}, 0.94 \mathrm{~kg} \mathrm{~m}^{-2} \mathrm{~h}^{-1}, 1.01 \mathrm{~kg} \mathrm{~m}^{-2} \mathrm{~h}^{-1}$, and $1.12 \mathrm{~kg}$ $\mathrm{m}^{-2} \mathrm{~h}^{-1}$. The enhancement factor of evaporation in the last three groups was 1.9 times, 2.1 times, and 2.3 times of that of the blank water group, shown in Fig. 4d.

$\mathbf{a}$

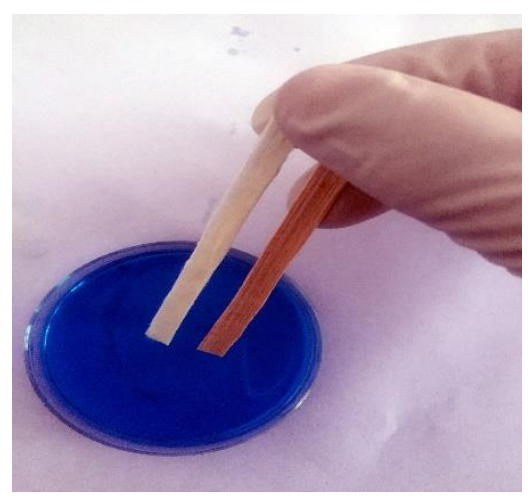

c

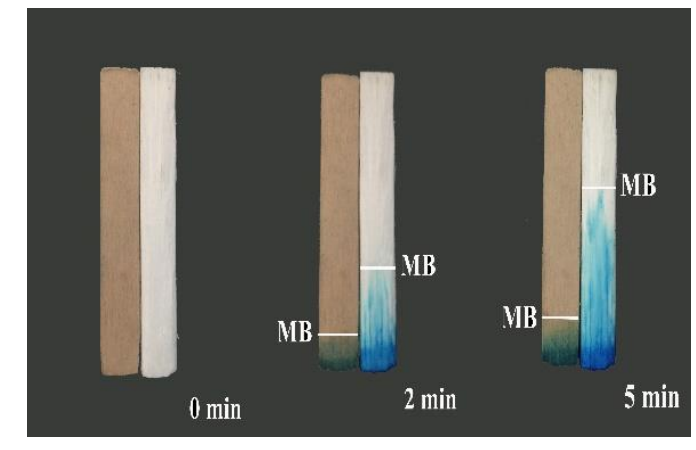

b
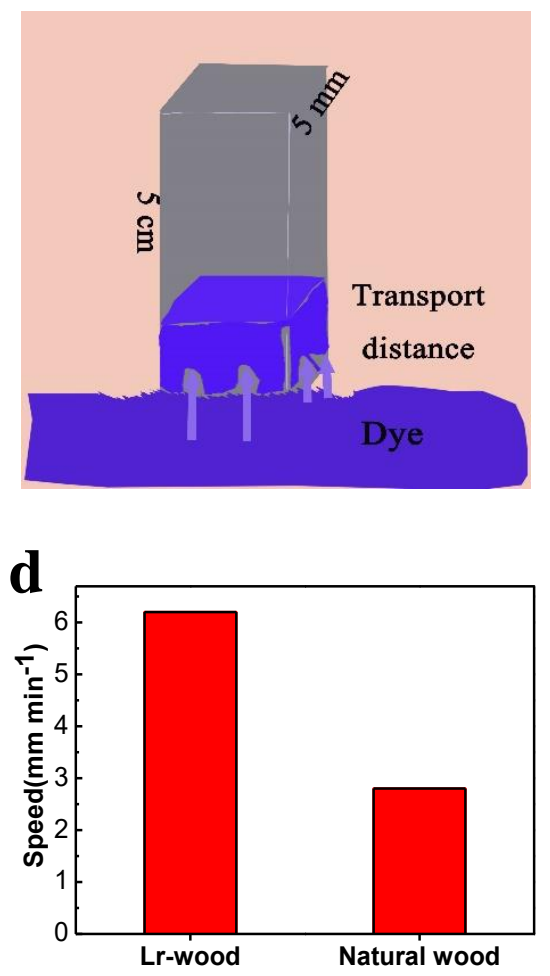

Fig. 3. (a) The experimental sketch and (b) brief comment of Methylene blue solution transport in DL- and natural wood. (c) The solution transport distances between DL- and natural wood for 0 $\min , 2 \mathrm{~min}$, and $5 \mathrm{~min}$. (d) The average solution transport speed between DL- and natural wood at the end of the $5^{\text {th }}$ min.

The amount of steam production of DL-wood/CNTs was higher than that of natural wood/CNTs by $20 \%$ under the same ambient sunlight. It can be seen that under the daytime sun illumination (1 sun), DL-wood/CNTs exhibited good performance for solar steam generation.

Thus, DL-wood/CNTs generated more steam than natural wood/CNTs, which greatly improves the efficiency of solar energy utilization. Under normal sunlight illumination (1 sun), the solar energy efficiency of DL-wood/CNTs devices reached 73\%, which was calculated using the following equation (Chen et al. 2017),

$$
\eta=m h_{L V} / \operatorname{Copt} \mathrm{P}_{0}
$$

where $m\left(\mathrm{~kg} \mathrm{~m}^{-2} \mathrm{~h}^{-1}\right)$ denotes the evaporation rate, Copt is the optical concentration, and $h_{L V}$ is the total enthalpy of the liquid-vapor phase transition including the sensible heat (Chen et al. 2017). Compared with the previously reported solar energy utilization rate of $65 \%$ under sunlight (1 sun), DL-wood/CNTs increased the efficiency by $8 \%$. This provides a potential, alternative device either steam power production or transmission, and it also opens up new paths for global energy issues that need to be solved. It should be noted that when the light intensity continuously increased from 1 to 10 suns, the steam generation efficiency gradually improved, and the solar energy utilization efficiency gradually improved (Chen et al. 2017). 

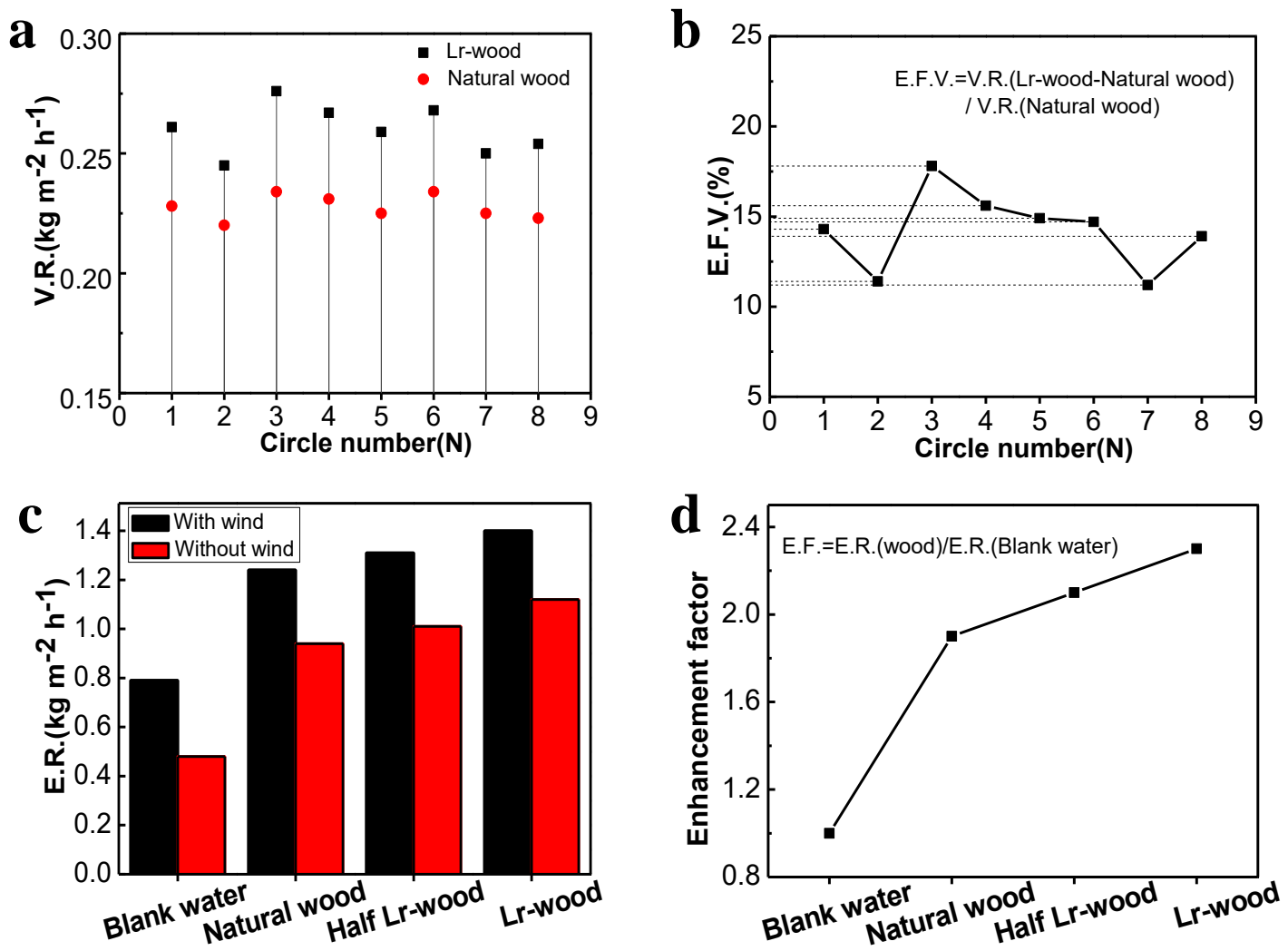

Fig. 4. (a) The volatilization rate (V.R.) of the material under normal daylight (1 sun); (b) the enhancement factor of evaporation of DL-wood vs natural wood; (c) the steam generation efficiency; and (d) the enhancement factor of DL-wood, half DL-wood, natural wood, and blank water control group.

a

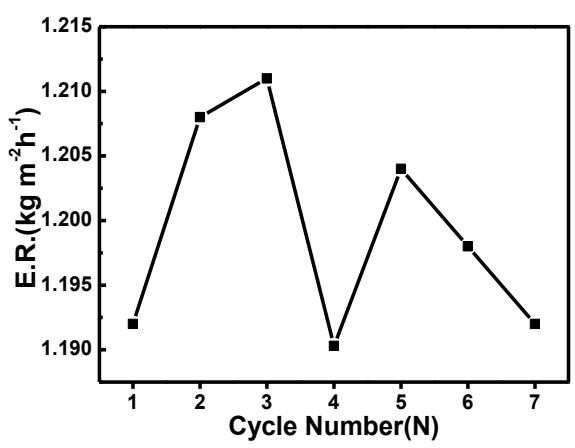

b

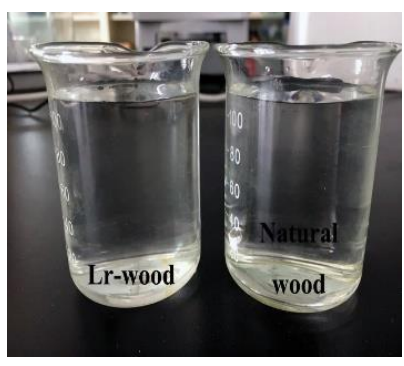

C

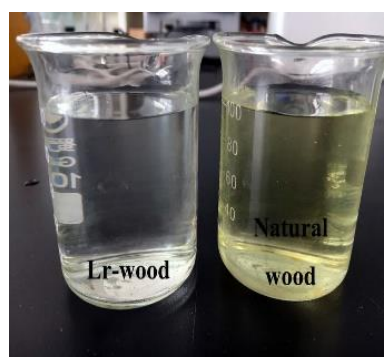

Fig. 5. (a) A cycle diagram of the evaporation rate of the DL-wood-based steam generation. Pictures of DL-wood and Natural Wood Devices (b) before and (c) after use.

To demonstrate the DL-wood-based steam generation stability, a cycle diagram of the evaporation rate is revealed in Fig. 5a. Since the mechanical strength was slightly reduced after the material was wetted, the principle of light handling is followed during use, so DL-wood/CNTs is not damaged and can be recycled. During the seven cycles of recycling, the DL-wood/CNTs device produced steam rates of $1.192 \mathrm{~kg} \mathrm{~m}^{-2} \mathrm{~h}^{-1}, 1.208 \mathrm{~kg}$ 
$\mathrm{m}^{-2} \mathrm{~h}^{-1}, 1.211 \mathrm{~kg} \mathrm{~m}^{-2} \mathrm{~h}^{-1}, 1.1903 \mathrm{~kg} \mathrm{~m}^{-2} \mathrm{~h}^{-1}, 1.204 \mathrm{~kg} \mathrm{~m}^{-2} \mathrm{~h}^{-1}, 1.198 \mathrm{~kg} \mathrm{~m}^{-2} \mathrm{~h}^{-1}$, and 1.192 $\mathrm{kg} \mathrm{m}^{-2} \mathrm{~h}^{-1}$, respectively. The above data demonstrated the good stability and recyclability of DL-wood/CNTs. Moreover, as seen in Fig. 5b and 5c, the evaporation devices before and after evaporation are shown to verify that DL-wood/CNTs device will not pollute the environment. It can be clearly identified that the solution after evaporation exhibits yellow color due to the leaching of natural wood. However, it is clean and pollution-free for DL-wood, and benign to the environment (He et al. 2019).

\section{CONCLUSIONS}

1. The steam generation efficiency of delignified wood (DL-wood) was improved in comparison to the default wood by increasing the water transportation and evaporation, which resulted from the removal of most hydrophobic lignin from natural wood. Under ambient sunlight, the steam generation efficiency of DL-wood with carbon nanotubes (CNTs) was about $20 \%$ higher than that of natural wood/CNTs.

2. Solar energy utilization of DL-wood/CNTs reached $73 \%$ under ambient sunlight. Compared with Hu's (Chen et al. 2017), DL-wood/CNTs increased thermal efficiency by $8 \%$.

3. When floating on water, DL-wood/CNTs will not fade so it will not further pollute water sources as natural wood do.

4. DL-wood/CNTs with the advantages of having low cost, simple design, mesoporous structure, and being environmentally friendly is originally proposed for solar steam generation.

\section{ACKNOWLEDGEMENTS}

The financial support for this research was provided by the Joint Special Project of Agricultural Basic Research in Yunnan (2017FG001036) and National Natural Science Foundation of China (41563008, 31100420).

\section{REFERENCES CITED}

Chen, C. J., Li, Y., Song, J., Yang, Z., Kuang, Y., Hitz, E., Jia, C., Gong, A., Jiang, F., Zhu, J. Y., Yang, B., Xie, J., and Hu, L. (2017). "Highly flexible and efficient solar steam generation device," Adv. Mater. 29(30), 1701756. DOI: 10.1002/adma.201701756

Gamelas, J. A. F., and Ferraz, E. (2015). "Composite films based on nanocellulose and nanoclay minerals as high strength materials with gas barrier capabilities: Key points and challenges," BioResources 10(4), 6310-6313. DOI: 10.15376/biores.10.4.63106313

Ghasemi, H., Ni, G., Marconnet, A. M., Loomis, J., Yerci, S., Miljkovic, N., and Chen, G. (2014). "Solar steam generation by heat localization," Nat. Commun. 5(1), 4449.

DOI: $10.1038 /$ ncomms 5449 
He, Y. M., Li, H. Y., Guo, X. L., and Zheng, R. B. (2019). "Bleached wood supports for floatable, recyclable, and efficient three dimensional photocatalyst," Catalysts 9(2), 115. DOI: $10.3390 /$ catal9020115

Ito, Y., Tanabe, Y., Han, J., Fujita, T., Tanigaki, K., and Chen, M. (2015). "Multifunctional porous graphene for high-efficiency steam generation by heat localization," $A d v$. Mater. 27(29), 4302-4307. DOI: 10.1002/adma.201501832

Jiang, Q., Tian, L., Liu, K. K., Tadepalli, S., Raliya, R., Biswas, P., Naik, R. R., and Singamaneni. S. (2016). "Bilayered biofoam for highly efficient solar steam generation," Adv. Mater. 28(42), 9400-9407. DOI: 10.1002/adma.201601819

Jin, H., Lin, G., Bai, L., Zeiny, A., and Wen. D. (2016)."Steam generation in a nanoparticle-based solar receiver," Nano Energy 28, 397-406. DOI: 10.1016/j.nanoen.2016.08.011

Li, H., Xu, W., Tang, M., Zhou, L., Zhu, B., Zhu, S., and Zhu, J. (2016). "Graphene oxide-based efficient and scalable solar desalination under one sun with a confined 2D water path," P. Natl. Acad. Sci. USA 113(49), 13953-13958. DOI: 10.1073/pnas.1613031113

Li, H. Y., Guo, X. L., He, Y. M., and Zheng, R. B. (2019). "A green, steam-modified delignification method to low lignin delignified wood for thick, large, highly transparent wood composites," J. Mater. Res. 2019. DOI: 10.1557/jmr.2018.466

Li, T., Liu, H., Zhao, X. P., Chen, G., Dai, J. Q., Pastel, G., Jia, C., Chen, C. J., Hitz, E., Siddhartha, D., Yang, R. G., and Hu, L. B. (2018). "Scalable and highly efficient mesoporous wood-based solar steam generation device: Localized heat, rapid water transport," Adv. Funct. Mater. 28(16), 1707134. DOI: 10.1002/adfm.201707134

Liu, H., Chen, C. J., Chen, G., Kuang, Y. D., Zhao, X. P., Song, J. W., Jia, C., Xu, X., Hitz, E., Xie, H., Wang, S. , Jiang, F., Li, T., Li, Y. J., Gong, A., Yang, R. G., Das, S., and $\mathrm{Hu}, \mathrm{L}$. B. (2017a). "High-performance solar seam device with layered channels: Artificial tree with a reversed design," Adv. Energy Mater. 8, 1701616. DOI: 10.1002/aenm.201701616

Liu, K., Jiang, Q., Tadepalli, S., Raliya, R., Biswas, P., Naik, R. R., and Singamaneni, S. (2017b). "Wood-graphene oxide composite for highly efficient solar steam generation and desalination," ACS Appl. Mater. Inter. 9(8), 7675-7681. DOI: 10.1021/acsami.7b01307

Ni, G., Li, G., Boriskina, S. V., Li, H., Yang, W., Zhang, T., and Chen, G. (2016). "Steam generation under one sun enabled by a floating structure with thermal concentration," Nature Energy 1(9), 16126. DOI: 10.1038/NENERGY.2016.126

Shi, L., Wang, Y., Zhang, L., and Wang, P. (2017). "Rational design of a bi-layered reduced graphene oxide film on polystyrene foam for solar-driven interfacial water evaporation," J. Mater. Chem. A 5(31), 16212-16219. DOI: 10.1039/C6TA09810J

TAPPI T222 om-11 (2011). “Acid-insoluble lignin in wood and pulp,” TAPPI Press, Atlanta, GA.

Wang, G., Fu, Y., Ma, X., Pi, W., Liu, D., and Wang, X. (2017). "Reusable reduced graphene oxide based double-layer system modified by polyethylenimine for solar steam generation," Carbon 114, 117-124. DOI: 10.1016/j.carbon.2016.11.071

Wang, G., Li, Y., Deng, L., Wei, N., Weng, Y., Dong, S., Qi, D., Qiu, J., Chen, X., and Wu, T. (2016a). "High-performance photothermal conversion of narrow-bandgap $\mathrm{Ti}_{2} \mathrm{O}_{3}$ nanoparticles," Adv. Mater. 29(3), 1603730. DOI: 10.1002/adma.201603730

Wang, Y., Zhang, L., and Wang, P. (2016b). "Self-floating carbon nanotube membrane on macroporous silica substrate for highly efficient solar-driven interfacial water 
evaporation," ACS Sustain. Chem. Eng. 4(3), 1223-1230. DOI:

10.1021/acssuschemeng.5b01274

Wright, R. S., Bond, B. H., and Chen, Z. (2013). "Steam bending of wood;

Embellishments to an ancient technique," BioResources 8(4), 4793-4796. DOI:

10.15376/biores.8.4.4793-4796

Xue, G. B., Liu, K., Chen, Q., Yang, P. H., Li, J., Ding, T. P., Duan, J. J., Qi, B., and Zhou, J. (2017). "Robust and low-cost flame-treated wood for high-performance solar steam generation," ACS Appl. Mater. Inter. 9(17), 15052-135057. DOI:

10.1021/acsami.7b01992

Yang, G. C., Chen, Z. W., Xie, Y. S., Wang, J., Elam, J. W., Li, W. H., and Darling, S. B. (2018). "Chinese ink: A powerful photothermal material for solar steam generation," Adv. Mater. Interfaces 1801252. DOI: 10.1002/admi.201801252

Zheng, R. B., Tshabalala, M. A., Li, Q., and Wang, H. (2015). "Weathering performance of wood coated with a combination of alkoxysilanes and rutile $\mathrm{TiO}_{2}$ heirarchical nanostructures," BioResources 10(4), 7053-7064. DOI: 10.15376/biores.10.4.70537064

Zheng, R. B., Tshabalala, M. A., Li, Q., and Wang, H. (2016). "Photocatalytic degradation of wood coated with a combination of rutile $\mathrm{TiO}_{2}$ nanostructures and low-surface free-energy materials," BioResources 11(1), 2393-2402.

DOI:10.15376/biores.11.1.2393-2402

Zhong, J., Huang, C., Wu, D., and Lin, Z. (2018a). "Influence factors of the evaporation rate of a solar steam generation system: A numerical study," Int. J. Heat Mass Tran. 128, 860-864. DOI: 10.1016/j.ijheatmasstransfer.2018.09.079

Zhong, J., Huang, C., and Wu, D. (2018b). "Surrounding effects on the evaporation efficiency of a bi-layered structure for solar steam generation," Applied Thermal Engineering 144, 331-341. DOI: 10.1016/j.applthermaleng.2018.08.074

Zhong, J., and Huang, C. (2019). "Crowding effects of nanoparticles on energy absorption in solar absorption coatings," J. Appl. Phys. 125(3), 033103. DOI: 10.1063/1.5064515

Zhou, L., Tan, Y., Ji, D., Zhu, B., Zhang, P., Xu, J., Gan, Q., Yu, Z., and Zhu, J. (2016a). "Self-assembly of highly efficient, broadband plasmonic absorbers for solar steam generation," Science Advances 2(4), e1501227-e1501227. DOI: 10.1126/sciadv.1501227

Zhou, L., Tan, Y., Wang, J., Xu, W., Yuan, Y., Cai, W., Zhu, S., and Zhu, J. (2016b). "3D self-assembly of aluminium nanoparticles for plasmon-enhanced solar desalination," Nat. Photonics 10(6), 393-398. DOI: 10.1038/NPHOTON.2016.75

Zhu, M. W., Li, Y. J., Chen, G., Jiang, F., Yang, Z., Luo, X. G., Wang, Y. B., Lacey, S. D., Dai, J. Q., Wang, C. W., Jia, C., Wan, J. Y., Yao, Y. G., Gong, A., Yang, B., Yu, S., Das, Z. F., and Hu, L. B. (2017). "Tree-inspired design for high-efficiency water extraction," Adv. Mater. 29(44), 1704107. DOI: 10.1002/adma.201704107

Zielinski, M. S., Choi, J.-W., Grange, T. La, Modestino, M., Hashemi, S. M. H., Pu, Y., Birkhold, S., Hubbell, J. A., and Psaltis, D. (2016). "Hollow mesoporous plasmonic nanoshells for enhanced solar vapor generation," Nano Lett. 16(4), 2159-2167. DOI: 10.1021/acs.nanolett.5b03901

Article submitted: Dec. 10, 2018; Peer review completed: Feb. 17, 2019; Revised version received: March 11, 2019; Accepted: March 16, 2019; Published: March 25, 2019. DOI: 10.15376/biores.14.2.3758-3767 